\title{
Common Logistics Center adoption in Korea's small and medium companies
}

\author{
Seock-Jin Hong*, Kwang-Seog Kim** and Choon-Woo Leem**
}

\begin{abstract}
This article reports on the current state of Common Logistics Center (CLC) adoption in Korea's industrial complex, identifies the benefits of and barriers of adopting Common Logistics Centers, and provides recommendations for the adoption/expansion of Common Logistics Centers. The author surveyed a cross-sectional of 175 firms in the industry, followed by interviews in an industrial complex in Incheon, Korea. The author founded the benefits and barriers of Common Logistics Centers and the major factors that encourage companies' participation.
\end{abstract}

Keywords: Common Logistics Center, benefits \& barriers factor, warehouse, distribution center.

* Professor, Bordeaux Management School, Corresponding Author. E-mail : Seockjin.hong@bem.due

** Director, Dept. of Airport, Port and Logistics, Incheon Metropolitan City. E-mail : Kim5579@incheon.go.kr

*** President of US Operations, CJ GLS. E-mail : samuelleem@hotmail.com 


\section{Introduction}

The increasing cost of logistics has been very burdensome to companies and obstructs economic activities by increasing consumer prices. It is very important to make efforts to discover benefits and barrier factors of Common Logistics Centers (CLC) ${ }^{1}$ under the situation of unnecessarily increased logistics costs. Improving competitiveness and saving logistics costs using CLCs for companies of small/medium size is absolutely critical. This study examined the substantial effects of CLCs. Logistics service users and providers have increasingly been making strategic partnerships to survive intensive competition in the global context. ${ }^{2}$ According to Sheffi (1990), companies in the U.S. are advised to commission a considerable portion of their logistics activities to third parties or build strategic partnerships or Common Logistics Center systems to survive competition, scale down budget, mitigate transportation regulations, and improve customer services. In Korea, there have been many studies on CLCs such as The Korea Industrial Complex Corporation (KICC, 2007-a, b) which conducted their research on a very limited number of industrial complexes for the Sihwa and Changwon Industrial Complex.

This study examined the necessity and revitalization of CLCs based on existing cases of Korea and the CLC of Namdong Industrial Complex in Incheon. Companies that are participating or not participating in the CLC of Namdong Industrial Complex were surveyed regarding the reasons, benefits, and barriers of CLCs. They were also surveyed on the contribution of CLCs to saving corporate logistics costs, the barriers, and the factors contributing to their decisions to participate in CLCs. The following sections of this article provide review of literature relating to warehousing, outsourcing, and CLCs; a description of methodological details including questionnaire design, sampling technique, and methods for analyzing data; results; and conclusions drawn from the findings.

\section{Literature Review}

According to the Logistics Policy Act in Korea, CLC means common use of facilities, equipment, human resources, organizations, and information networks by logistics companies or shippers for more efficient logistics activities. Common shipping through CLCs increases loading efficiency of containers and reduces the number of shipments through shipping goods together by area or type of goods. This increase enables reasonable transportation

\footnotetext{
1 Trading arrangements which depart from the fundamental principle of non-discrimination are permitted under various provisions of the GATT/WTO (for example Article XXIV of the GATT). Such agreements are sometimes described as free trade areas (FTAs) or regional trading arrangements (RTAs). This paper describes them as preferential trading arrangements (PTAs), since they involve discrimination among trading partners.
}

2 Mehta, Larsen \& Rosenbloom, 1996 
control. Also, product processing, packaging, and shipping are jointly processed to revitalize product flow, share professional manpower, and maximize space efficiency. As a result, the overall cost of distribution and logistics is reduced. In particular, participating companies can build a logistics network to manage data, save cost of purchasing through common purchase, and control product supply to contribute to stabilization of prices.

According to Langley and Capgemini (2007), domestic transportation (83\%), international transportation (79\%) and warehousing (69\%) comprise the largest portion of third-party outsourcing in each company's logistics services. Other services with $50 \%$ or more outsourcing were customs (67\%) and forwarding (51\%). Outsourcing in logistics is also found in shipment consolidation, packaging, labeling, assembly, transportation control, reverse logistics, and cross-docking. About two thirds of responders stated that the reason for using logistics outsourcing is because it offers new and innovative ways to improve the effectiveness of logistics services, thus having positive influence on customer services.

KICC (2007-a) analyzed the operation performances and effectiveness of common warehouses of local companies. Shippers using common warehouses were surveyed to examine their overall satisfaction, as well as their participation in and satisfaction with logistics system training. Then, the effectiveness of these participants' logistics before and after participation was compared. Incheon Metropolitan City (2007) presented problems and complaints discovered during the testing period (2005-2007) for the future improvement issues of CLC. Goal achievement, customer attraction, usability of common logistics centers, and varieties of logistics services were assessed based on 14 assessment indexes. This report particularly asserts that local government support shall cease and the CLC shall be privatized. For areas of future expansion, it proposes international complex transportation services, customized consultations, online malls exclusively for participants, procurement logistics services, and simplification of distribution procedures.

Lee (2004) analyzed O/D (Origin and Destination) quantities and demand for CLCs at national industrial complexes. Kim et al. (2008) emphasize the importance of strengthening services and logistics competence to keep up with the rapid development and changes of the logistics market. They pointed out that more companies tend to use logistics centers of specialized service providers instead of owning independent logistics centers for simple operations. In other words, logistics centers are being integrated and concentrated, rather than using several dispersed warehouses in each locality. Thus, logistics centers are expanding in scale and increasing the efficiency of land use as land prices rise. Kim et al. state their opinions on the development of high-rise logistics centers and the increasing demand for standardized facilities.

KIET (1998) suggests that in order to overcome the weaknesses of common logistics centers, it is necessary to operate common logistics centers by specialized service providers, rather than building common use systems through consortiums of manufacturers and transporters. He insists that it is important to establish and operate logistics centers that can 
provide advanced services to companies and offer both storage and distribution services. Kim (1998) suggests CLCs for companies in the same region. Also, he examined transportation/ shipping, storage only, and storage and distribution through CLCs as areas are available. He particularly emphasized complete distribution systems for small and /medium companies.

The Korea Warehouse Association (2008) emphasized that logistics centers in Korea must quickly convert to larger scales, complex functions, improvement, and environmentalfriendliness as it is the international trend to develop complete logistics services and high value-added logistics that are larger in scale and provide various logistics services through third-party and fourth-party logistics. Most logistics centers in Korea are concentrated in the metropolitan area; Seoul metropolitan area 67.3\%, Busan metropolitan area 12.3\%, Ulsan and the south-east region 7.4\%, Daejun and the mid-west region 5.5\%. The average warehouse size is $8,179 \mathrm{~m}^{2}$ and $88.3 \%$ are cooperatives. Also, $69.1 \%$ of warehouses are owned by private companies and $30.9 \%$ are rented. Considering capital and sales, most logistics centers in Korea are quite small-sized. Six out of ten have 1 million dollars or less capital and $72 \%$ record 5 million dollars or less in sales. For the advancement and development of logistics facilities in Korea, it is necessary to enhance efficiency of operation and provide policy support to increase scale.

Lee (1997) combined the common logistics centers established by the Korea Supermarket Association (KOSA) for purchasing and logistics services at each local cooperative and implemented common purchasing and logistics to supply goods and services to association members at low costs. It was not a mere combination of logistics, but a type of logistics rationalization to save through common purchasing and common logistics. As a result, the logistics cost of cooperatives was reduced to $5 \%$ from over $10 \%$ of sales.

The CLCs could offer very quick and stable logistics services to all participants regardless of the fluctuation of quantities in different months or seasons. The participants have gained more trust from customers and are seeing increased orders. Tate (1996) pointed out that the trust of participants is an important key to success in CLCs. Lambert and Stock (1993) emphasized the traditional relationship between shippers and logistics service providers. The relationship requires continuity of mutually close interaction and symbiosis through cooperation or strategic partnership which shall be built with CLCs for mutual benefits. As companies realize mutual benefits through cooperation, the number of partnerships or cooperative relationships is increasing every year. In these contexts, CLCs are so natural due to the sharing of resources, facilities, and infrastructures, including information systems, with several other companies. 


\section{Research Method}

CLCs are promoted due to the changes in industrial and business environments. Furthermore, small and /medium companies do not have enough capital to build independent networks, warehouses, or distribution centers. In fact, warehousing is a traditional service. Also, it is the first category discussed when considering logistics outsourcing. It can be the greatest source of value added as advanced technologies and innovative methodologies, such as cross-docking, labeling, and common use of logistics centers, can be used to increase value added. The CLC managed by local government allows its participating small/medium companies to save investments in warehouse facilities and execute shipping at a common hub. In particular, the CLC operators develop various logistics service programs, such as quality control service, training system, customer monitoring system, customer claim processing system, and voice of customer. Also, air quality and traffic congestion issues improves as vehicle transportation is reduced.

To find the reasons, benefits, and barriers of CLC participation at the Namdong industrial complex in Incheon, the author designed a survey questionnaire to collect information from companies at Namdong industrial complex of Incheon regarding their perception of the CLC which has been established at the complex since 2005. The research process of this study comprises a review of related literature, questionnaire development through interviews with academics and practitioners in logistics, data collection, and analysis including one sample t-test, factor analysis, and regression analysis. The factors of the questionnaire were referred to mainly on Langley and Capgemini (2007). Furthermore, additional factors were calculated after interviews with industry experts. A total of 4,243 companies were identified, most of them are small and medium sized companies. From the list 117 companies were selected which have or had participated in CLC and have or had an intention to participate, 20 companies using CLCs, with 48 logistics companies located at Incheon Port, and 10 shippers that are operating at Incheon Port.

The authors met directly with one of the persons who had at least 3 years experiences or more at their respective companies. So, the target respondents were assumed to have a good knowledge of their business and the CLC's function. Types of businesses were wooden furniture $(17.7 \%)$, electronics $(14.9 \%)$, mechanical equipment $(13.1 \%)$, automotive parts $(12.8 \%)$, chemical products $(8.6 \%)$, and others, including fiber, plastic, metal, and glass (33.1\%). Most of the companies were operating in the metropolitan area (64.6\%), but there were also nationwide businesses (14.9\%) and businesses in the south-east region (Yeongnam, 9.14\%). The ratio of businesses in the mid-west region (Chungcheon) was $8 \%$. The units of packaging of companies participating or willing to participate in the Common Logistics Center were boxes $(34.3 \%)$, pallets $(28.6 \%)$, CBM (19.4\%), containers (11.4\%), and other (bulk and tonnage, 6.3\%). The sales scale of these companies was mostly in the range of 2 to 10 million US dollars (37.1\%), but there were other small/medium companies with sales 
below 2 million (15.4\%), 10 to 30 million (22.7\%), 30 to 100 million (14.3\%), or over 100 million $(11.4 \%)$. The length of experience of responders which was less then 3 years at $17.7 \%$, between 3 and 6 years at $24.6 \%$, between 6 and 10 years at $15.4 \%$, between 10 and 15 years at $16.6 \%$, and over 15 years at $25.7 \%$. Their positions were employees $(16.6 \%)$, assistant managers $(12 \%)$, managers $(21.7 \%)$, assistant directors/directors $(29.1 \%)$, or CEO/executives (20.6\%).

\section{Results and Analyses}

The major reasons for participation in CLC was examined on a likert scale of one through five. It was found that the most critical factors were "operator's quick response (4.46), cost-saving capacity (4.39), professional manpower and expertise (4.16), high flexibility (4.15), sustainable relationship (4.11), and various services (4.05)." The least contributive factor was "operation by a large and financially stable logistics company (3.65)." Thus, it was concluded that participants demand a Common Logistics Center system through which they can provide quality and timely services to customers. However, the financial stability of the operators was not a critical factor. As a result of one sample t-test for 3.5 points or higher (above average), there were statistically significant results in all nine categories. Thus, all of these nine categories were considered the most important factors out of contributing to the companies' decision to participate in CLC.

Table 1.

Perceived Major Reasons for Participation in CLCs ( $\mathrm{N}=175$ )

\begin{tabular}{l|c|c}
\hline \multicolumn{1}{c|}{ Reasons } & Average & Standard Deviation. \\
\hline \hline Quick response & $4.46^{* * *}$ & 0.698 \\
\hline Cost-saving capacity & $4.39^{* * *}$ & 0.757 \\
\hline Professional manpower and expertise & $4.16^{* * *}$ & 0.767 \\
\hline High flexibility & $4.15^{* * *}$ & 0.690 \\
\hline Sustainable relationship & $4.11^{* * *}$ & 0.810 \\
\hline Various services & $4.05^{* * *}$ & 0.773 \\
\hline Advanced logistics system & $4.03^{* * *}$ & 0.930 \\
\hline Recognition & $3.73^{* *}$ & 1.039 \\
\hline Large logistics operator (financial) & $3.65^{*}$ & 0.976 \\
\hline
\end{tabular}

Note: 5 points (very critical) $\leftrightarrow 3$ points (average) $\leftrightarrow 1$ points (not critical)

$* \mathrm{P}<0.05, * * \mathrm{P}<0.01, * * * \mathrm{P}<0.001$ 
The benefits of participation in CLCs were examined on a scale of one through five. As a result, the enhancement of customer service was found to be the most important factor (4.26). Other important factors were the reduction of transportation costs and the increase in vehicle rotation (3.96). The improvement of corporate competitiveness came to 3.90 and the improvement of internal processes for warehouses reached 3.82. However, the enhancement of collaboration (3.43) was of lowest importance. These results are shown in Table 2. The result of a one-sample t-test at 3.5 was determined, also for the benefits of CLC. As a result, enhance collaboration, reduce risk and pursue common benefit through cooperation, and eliminate waste factors were not found beneficial for participators. The characteristics of common concepts were examined through factor analysis ${ }^{3}$ based on the relativity of variables while minimizing the loss of data, refer to Table 3 . As a result, the factors were classified into two areas such as "strategic cooperation and efficiency" and "improving internal process and economic value."

Table 2.

Perceived Benefits of Participation with CLCs (N=175)

\begin{tabular}{l|c|c}
\hline \multirow{2}{*}{ Benefit Factors } & \multicolumn{2}{c}{ Importance } \\
\cline { 2 - 3 } & Mean & S.D. \\
\hline \hline Enhances customer service & $4.26 * * *$ & 0.77 \\
\hline Reduce transportation cost and increase vehicle rotation & $3.95 * * *$ & 0.79 \\
\hline Improve corporate competitiveness & $3.90 * * *$ & 0.80 \\
\hline Improve internal process for warehouse & $3.82 * * *$ & 0.92 \\
\hline Maximize profit & $3.80 * * *$ & 0.86 \\
\hline Concentrate on corporate competencies & $3.74 * *$ & 0.99 \\
\hline Share logistics infrastructure & $3.72 * *$ & 0.93 \\
\hline Eliminate wastes & 3.66 & 1.08 \\
\hline Reduce risk and purse common benefit through cooperation & 3.61 & 0.90 \\
\hline Enhance collaboration & 3.43 & 0.89 \\
\hline
\end{tabular}

Note: 5 points (very critical) $\leftrightarrow 3$ points (average) $\leftrightarrow 1$ points (not critical)

Regression analysis was implemented on the results of factor analysis and on the overall satisfaction with CLCs as seen in Table 4. The resulting $\mathrm{R}^{2}$ of regression analysis was 0.55 , meaning that the coefficients of improving internal process and economic value were statistically significant. In other words, the companies participating in Incheon

${ }^{3}$ KMO 0.891, p-value 0.000 
Namdong Industrial Complex's CLC tend to value improving internal processes rather than strategic cooperation or efficiency. In other words, CLCs emphasize improving internal processes for human/material resources, saving time and cost, improving customer services, creating a better environment, reducing traffic congestion, reducing stocks, increasing transportation, and cleaning up the work area. Thus, there must be investment in strengthening competitiveness, concentrating key capacities, and removing waste factors in the future. The most effective factor for the efficiency of logistics and saving the cost of logistics is saving the cost of logistics per unit by increasing scale and synergies. CLCs ares not all that is needed for small and medium businesses at Incheon Namdong Industrial Complex to significantly increase quantity of transportation. These companies must establish strategic partnerships within the industry or with other industries to realize common logistics and to strategically reduce the cost of logistics. They must search for every possible opportunity of CLC with other companies, industries, and regions to contribute to the national strength of Korea.

Table 3.

Results of Factor Analysis

\begin{tabular}{l|c|c}
\hline \multirow{2}{*}{ Benefit Factors } & \multicolumn{2}{|c}{ Factors } \\
\cline { 2 - 3 } & $\begin{array}{c}\text { Strategic Cooperation and } \\
\text { Efficiency }\end{array}$ & $\begin{array}{c}\text { Improving Intemal } \\
\text { Process and Economic } \\
\text { Value }\end{array}$ \\
\hline \hline Enhances customer service & 0.10 & $\mathbf{0 . 8 2}$ \\
\hline $\begin{array}{l}\text { Improve internal process for } \\
\text { warehouse }\end{array}$ & 0.29 & $\mathbf{0 . 6 8}$ \\
\hline $\begin{array}{l}\text { Reduce transportation cost and } \\
\text { increase vehicle rotation }\end{array}$ & 0.21 & $\mathbf{0 . 7 4}$ \\
\hline Maximize profit & 0.48 & $\mathbf{0 . 5 5}$ \\
\hline Share logistics infrastructure & $\mathbf{0 . 6 7}$ & 0.38 \\
\hline Enhance collaboration & $\mathbf{0 . 7 5}$ & 0.21 \\
\hline $\begin{array}{l}\text { Reduce risk and purse common } \\
\text { benefit through cooperation }\end{array}$ & $\mathbf{0 . 7 2}$ & 0.21 \\
\hline Improve corporate competitiveness & $\mathbf{0 . 5 2}$ & 0.47 \\
\hline $\begin{array}{l}\text { Concentrate on corporate } \\
\text { competencies }\end{array}$ & $\mathbf{0 . 7 4}$ & 0.24 \\
\hline Eliminate waste factors & $\mathbf{0 . 7 9}$ & 0.14 \\
\hline & & \begin{tabular}{c}
$\mid c$ \\
\hline
\end{tabular}
\end{tabular}


Table 4.

Results of Regression Analysis with Factor Analysis

\begin{tabular}{c|c|c|c|c}
\hline Model & $\begin{array}{c}\text { Non-standardized } \\
\text { Coefficient } \boldsymbol{\beta}\end{array}$ & $\begin{array}{c}\text { Standardized } \\
\text { Error }\end{array}$ & $\begin{array}{c}\text { Standardized } \\
\text { Coefficient } \boldsymbol{\beta}\end{array}$ & $\mathbf{T}$ \\
\hline \hline (Constant) & 3.96 & 0.14 & & $28.22 * * *$ \\
\hline $\begin{array}{c}\text { Strategic Cooperation } \\
\text { and Efficiency }\end{array}$ & 0.23 & 0.14 & 0.27 & 1.64 \\
\hline $\begin{array}{c}\text { Improving Internal } \\
\text { Process and Economic } \\
\text { Value }\end{array}$ & 0.66 & 0.16 & 0.69 & $4.25^{* *}$ \\
\hline
\end{tabular}

Note: Dependent Variable: Overall Satisfaction of Participating Companies / ** $\mathrm{P}<0.01,{ }^{* * *} \mathrm{P}<0.001$

The most substantial outcome of CLCs is saving on the cost of logistics. The cost of logistics makes up a big portion of manufacturing costs, especially in companies that are small and medium in size. CLCs should be promoted to expand corporate capacities. Third-party commissioning in logistics shall be used in purchasing and sales to minimize the overhead costs of the company and to be able to concentrate on production for the manufacturer. In other words, improved efficiency in logistics can save costs and improve competitiveness. Outsourcing and CLCs are ways to realize this. In the future, common logistics centers must adopt advanced equipment and information systems. High productivity and fixed density can be realized by connecting the networks of participating companies through an advanced information system. By eliminating waste factors and improving international processes in these ways, companies would be able to reduce the operation of unfilled vehicles and increase loading efficiency to generate profits.

There are various barriers against CLCs, but the most worrisome issues were "difficulty in managing products, lack of control over shipping time, risk of damage, and possibility of disputes pertaining to profit distribution (4.06)." Other worrisome issues were "leak of confidential information (client profile, sales performance, etc) (3.86)," "doubts in cost-saving capacity of CLC (3.86)," "impossibility to execute sales activities as needed and lack of passion and sense of responsibility as vehicles are not owned (3.79)," and "difficulties in executing independent sales activities, expanding sales channels, and worries in quality of service (3.63)." 
Table 5.

Perceived Barriers of Participation in CLCs using One -Sample T-test (at 3.5 points)

\begin{tabular}{l|c|c|c}
\hline \multicolumn{1}{c|}{ Barriers } & N & Mean & S.D. \\
\hline \hline Difficulty in managing products (Damage, profit share etc.) & 155 & $4.06^{* * *}$ & 0.85 \\
\hline Lack of Commitment involving of Common Logistics Center & 155 & $3.86^{* * *}$ & 0.86 \\
\hline Fear of confidential clients' information & 155 & $3.86^{* * *}$ & 1.06 \\
\hline Lack of flexibility not use own vehicles & 155 & $3.79 * * *$ & 0.91 \\
\hline $\begin{array}{l}\text { Difficulty independent sales activities, and worries in quality of } \\
\text { service }\end{array}$ & 155 & 3.63 & 0.94 \\
\hline
\end{tabular}

Note: $* \mathrm{P}<0.05, * * * \mathrm{P}<0.001$

Among the barriers against CLC, there was a difference in awareness of "impossibility to execute sales activities as needed and lack of passion and sense of responsibility" depending on the position of the respondent. This item was considered the most critical obstacle among onsite workers (assistant managers and managers). As a result of one -sample t-test at 3.50 on the five barriers against Common Logistics Centers, it was found that "difficulties in executing independent sales activities, expanding sales channels, and worries in quality of service" were not considered an obstacle as shown in Table 5. In other words, only the remaining four items are considered barriers against Common Logistics Centers.

Most companies at Namdong Industrial Complex, except for large companies, have problems with lack of storage or work space. Focused on solving this problem, a test project of CLCs at Namdong Industrial Complex was launched in September, 2005. Participating companies received third-party logistics services, storage, and shipping services. The test project offered storage services that were about $40-80 \%$ more affordable, with an average monthly rent of $25 \$ 3.3 \mathrm{~m}^{2}$. Also, shipping services are offered about $60-70 \%$ cheaper. These services are contributing to their logistics strength. Participating companies have enjoyed services and benefits in common storage, common shipping, logistics consultations, logistics information systems, picking, packing, labeling, installation, assembly, after-sale services, procurement logistics, and import/export logistics through CLCs.

The roles of logistics service providers have expanded from simple transportation and storage to high value-added logistics including assembly and processing. In particular, the logistics industry has become an important part of the national industry of Korea. It is a fact that companies expect to learn from operators by participating in CLCs operated by recognized operators. It is believed that operators' services, expertise and professional manpower in logistics contribute to saving, quick responses, and flexibility. Barriers against 
CLCs were doubts in cost-saving capacity, difficulty in managing products, difficulty in providing customized services, risk of damage, leak of confidential information, and worries in quality of service due to the fact that senders cannot execute any sales activities. Therefore, it was necessary to establish strategic marketing activities to promote the idea that participation in CLCs has many benefits. CLCs maximize the efficiency of storage and are characterized by value-added services for companies and customers using customeroriented and technology-intensive characters. They can even shorten the length of logistics channels, improve overall efficiency, and save companies money. Therefore, it was concluded that CLCs should be introduced, operated, and revitalized for small and medium companies to help them gain competitiveness and concentrate on their key capacities.

\section{Conclusion}

Incheon Namdong Industrial Complex's CLC was started to help companies save on the cost of logistics and to improve their competitiveness. It was also to provide the companies with larger storage and work spaces. By doing so, the companies were allowed to reduce fluctuation in quantities in different months and seasons, improve service capacities and reliability, and provide stable logistics services. This study understood the benefits and barriers discovered during the survey period and suggested future improvement measures and development directions. The local government of Incheon was willing to provide both administrative and financial support. Many companies at Namdong Industrial Complex were positive about the CLC and considered it a successful project. However, in order to settle CLC, it is necessary to consider establishing an appropriately sized logistics center. CLCs maximize efficiency and provide value-added services to companies and customers in additional storage services. Participants shorten the length of logistics channels, improve overall efficiency, and save money. An advanced information system should be built to share transaction information between suppliers and manufacturers, order information between consumers and manufacturers, and ship information between transporters and logistics centers.

The logistics centers should be used as cross-docking spaces for small and medium companies to solve problems with lack of space for storage and work. More companies should use CLCs when they need to solve existing problems, generate more profits, and gain competitiveness. The purpose of CLCs is to provide quality services that actually contribute to participating companies, rather than generating profits. Quality services should be built on trust between service providers and users as stated by Hong et al. (2007). Trust-based partnerships the key to the continuing success of CLCs. In the future, the scope of Common Logistics Center services shall expand to international transportation and customized consulting services for each type of participating business. 


\section{References}

Hong, S. J., Kwon, I. W., and Kim, M. S. 2007. A Study on Impact of Trust in Supply Chain Partnership, Korea Logistics Review, 17(3): 119-139.

Incheon Metropolitan City. 2008. Three-phase Development Plan for Namdong Industrial Complex Common Logistics Center Project.

Incheon Metropolitan City. 2007. Namdong Industrial Complex Common Logistics Center Test Project Evaluation Report.

Kim, S. H. 1998. Study on Facts on and Demands for Common Logistics Center, Korea Chamber of Commerce.

Kim, Y. J., Min, J. Y., and Ha, H. G. 2008. Understanding Logistics Technology and Security, Jungseok Research Institute.

The Korea Industrial Complex Corporation (KICC). 2007-a. The Korea Industrial Complex Corporation's Common Logistics Center Test Project Performance Report.

The Korea Industrial Complex Corporation (KICC). 2007-b. Report on Common Logistics Center at Industrial Complexes.

Korea Institute for Industrial Economics and Trade (KIET). 1998. Study on Manufacturers' Common Logistics Center.

Langley, J. and Capgemini. 2007. 2007 Third-Party Logistics; The State of Logistics Outsourcing-Results and Findings of the 12th Annual Study, Capgemini, Georgia Tech, SAP, DHL.

Lambert D. M. and Stock J. R. 1993. Strategic Logistics Management (3rd ed.), Richard D, Irwin Inc.

Lee, G. Y. 1997. Samsung C\&T's Common Logistics Center for Small/Medium Distributors, Korean Journal of Logistics, 5(1): 135-151.

Lee, H. J. 2004. Understanding Logistics and Common Warehouse Strategies in the 21st Century, Dunam Press.

Lee, S. G. 2005. Study on Building Common Logistics Center, Samyoung Logistics Co.

Lee, S. I. 2008. Study on Rationalization of Common Logistics Center in Korea's Paint Industry, Korea Logistics Review, 18(1): 179-199.

Metha, R., Larsen T. and Rosenbloom, B. 1996. The Influence of Leadership Style on Co-operation in Channel of Distribution, The International Journal of Physical Distribution \& Logistics Management, 26(6): 32-59.

Sheffi, Y. 1990. Third Party Logistics: Present and Future Prospects, Journal of Business Logistics, 11(2): 27-39.

Tate, K. 1996. The Elements of a Successful Logistics Partnership, The International Journal of Physical Distribution \& Logistics Management, 26(3): 7-13. 